Paulo Freire Mello

Doutorando em Desenvolvimento Rural PGDR/UFRS. Engenheiro Agrônomo do INCRA/RS.E-mail: paulo.mello@poa.incra.gov.br

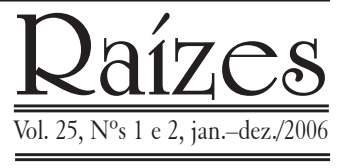

Trabalho recebido em: 26/07/2006

Aprovado para publicação em: 20/04/2007

\title{
ROTATIVIDADE EM ASSENTAMENTOS RURAIS ${ }^{1}$
}

\section{ROTATING IN RURAL SETTLEMENTS}

Apresentamos o fenômeno da rotatividade em 193 assentamentos no Estado do Rio Grande do Sul, com ênfase na evasão de lotes. Não encontramos correlação da evasão com as variáveis relacionadas à dimensão material. Os resultados revelaram uma estimativa de $22 \%$ de evasão, porém com diferenças regionais acentuadas. O estado civil e a religião foram relacionados à evasão em duas etnografias e nos permitiram verificar que esta é estancada em situações de maior coesão social, relacionadas às relações de reciprocidade, em especial, o parentesco, na forma da família extensa e do compadrio, e às relações religiosas e de vizinhança.

Palavras-chave: rotatividade, evasão, coesão social

\section{ABSTRACT}

We present the rotating phenomenon in 193 settlements of Rio Grande do Sul, with emphasis in parcels escape. W did not find scape correlacion with factors related to the material dimension. The results revealed a 22\% scape estimative, but with great regional differences. The civil state and religion were related to scape in two ethnographic cases and permited us to verify the scape is stopped in bigger cohesion social situacions, related to reciprocity relationship, in special, the kinship, in extend family and "compadrio" form, and to neighbor and religious relationship.

Key words: rotating, scape, social cohesion

\footnotetext{
1 O artigo é parte de um estudo maior: Evasão e rotatividade em assentamentos rurais no Rio Grande do Sul, desenvolvido pelo autor em 2006.
} 


\section{Paulo Freire Mello}

\section{INTRODUÇÃO}

Grande parte dos estudos sobre assentamentos rurais ${ }^{2}$ tende a minimizar o tema da evasão nos assentamentos, tida, muitas vezes, como baixa, normal e aceitável. Este trabalho nasceu da necessidade de dar conta deste tema, que apresenta, na nossa opinião, relevância cada vez maior para a sociedade brasileira e para os estudiosos e trabalhadores da área, na medida em que nos impele a pensar as novas dinâmicas da reforma agrária brasileira. Partimos do pressuposto de que os assentamentos de reforma agrária, enquanto política essencialmente social, são uma opção interessante para os pobres do Brasil. Entretanto, para uma melhor consecução desta política pública, urge uma maior compreensão dos fenômenos sociais que ocorrem nos assentamentos, tais como os que levam as famílias à evasão ou ao trânsito entre os mesmos. Deve-se registrar que a idéia de evasão é utilizada aqui genericamente, sem distinção se ela representa abandono, venda ou expulsão, até porque os dados secundários utilizados não permitem esta separação.

Contudo, a mobilidade dos assentados não se restringe à evasão. Nos estudos de caso, observamos que outras situações têm ocorrência relevante, tais como as mortes por conflito, as trocas de lotes entre e intra-assentamentos; as trocas de titularidade ou mesmo o abandono de lotes ocupados irregularmente, o que nos levou a alargar a análise, buscando compreender um fenômeno maior, a rotatividade, abarcando todas estas situações de saídas. O termo evasão caracteriza, de forma precisa, a fuga ou a saída da política de reforma agrária, enquanto os demais demonstram a mobilidade dos assentados dentro ou à margem da reforma agrária.

No Rio Grande do Sul, em 2005, havia 292 assentamentos de reforma agrária, criados ou reconhecidos pelo INCRA ${ }^{3}$, englobando cerca de 11.000 lotes. Quantificamos em 22\% o índice médio de evasão de 193 assentamentos (Mello, 2006). A rotatividade e a evasão de lotes, como pretendemos demonstrar, embora tendo múltiplas causas, são potencializadas em situações de baixa coesão social. Desta forma, os assentamentos que conseguem estabelecer uma maior coesão social apresentam mais possibilidades de evitá-las. Apresentamos aqui, de forma resumida, como chegamos a esta conclusão.

\section{O ÊXODO RURAL E A UNIFICAÇÃO SIMBÓLICA}

A evasão do campo não é um privilégio dos assentados. Em recente estudo com a juventude rural do Rio Grande do Sul, Brumer et al. (2002) procuraram explicar as migrações e concluíram que eram estimuladas nas propriedades que apresentavam dificuldades para a obtenção de renda. Porém, é preciso considerar os aspectos simbólicos deste processo. Bourdieu (2000), estudando o campesinato francês, na década de 1970, constatou que a subordinação da economia camponesa ao mercado veio junto com o enfraquecimento da resistência camponesa no mercado simbólico. A balança pendia para o modo de vida da cidade, onde o salário melhor era uma dimensão, entre outras, mas o fundamental era a mudança de valores e desejos, para que as vantagens oferecidas fossem percebidas e apreciadas. Foi a ação do poder simbólico que efetuou uma conversão coletiva da visão de mundo, feita em etapas, para que se operassem as mudanças psíquicas necessárias. Empregos de meio-turno na cidade, por exemplo, poderiam representar o início de um processo irreversível. Esta trajetória psicológica era percorrida mais rapidamente por aqueles elementos menos apegados à condição camponesa e à terra, notadamente as mulheres, os filhos mais moços (pois não eram os herdeiros naturais, no caso específico) e os mais pobres, todos mais propensos à emigração.

Essa espécie de força de atração das cidades se inscreve num processo maior, definido por Elias (1994), de individualização nas sociedades modernas, onde o que ele chamou de identidade "nós" tinha papel central nas sociedades antigas, em oposição à identidade "eu”, a qual só surgiu no Renascimento, assim como a própria idéia de indivíduo.

A existência da identidade "nós”, contudo, não significa dizer que não havia conflito, mas que sobreviviam somente os grupos que conseguiam chegar a um modus vivendi, a um certo equilíbrio entre a cooperação e o conflito. Aqui parece se configurar uma importante meta para o desenvolvimento dos assentamentos, ao nos darmos conta de que, mais do que uma questão econômica, a busca por um equilíbrio na sociabilidade parece ser crucial em locais conflituosos, como costumam ser estes locais. Em outras palavras, pretendemos demonstrar que o assentamento, à medida que sua balança identitária pende para

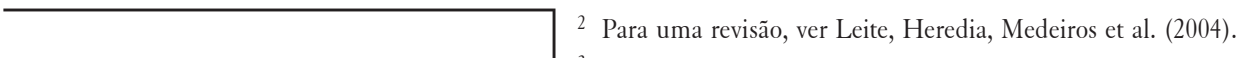

3 Instituto Nacional de Colonização e Reforma Agrária, órgão de terras federal.
} 
“nós”, tende a alcançar uma maior estabilidade e, com isso, uma menor evasão.

Corroborando com esta idéia, alguns estudos ${ }^{4}$ sobre evasão em assentamentos brasileiros apontam para a necessidade de exploração do tema das comunidades, isto é, da possibilidade de formação da coesão social, mais do que dos fatores materiais envolvidos, sublinhando a resistência à unificação simbólica do mundo urbano e rural descrita acima.

\section{O MÉTODO}

Para prospectar as causas de evasão, foram testadas 16 variáveis: a falta ou atraso de infra-estrutura e do crédito, medida pelo tempo transcorrido entre as datas de criação dos assentamentos e as datas correspondentes à aquisição de três linhas de crédito: a) crédito instalação, modalidade apoio, b) crédito instalação, modalidade materiais de construção e c) PRONAF A $\mathrm{A}^{5}$; d) percentual dos lotes sem água, e) percentual dos lotes sem luz, f) percentual dos lotes sem casa, g) percentual das estradas internas executadas e; h) percentual das estradas externas em má condição; i) a qualidade dos solos (medida pelo percentual de classes de capacidade de uso I a IV); j) tipo de assistência técnica (EMATER ${ }^{6}$ ou COPTEC ${ }^{7}$ ); l) executor do assentamento (INCRA, GRAC ${ }^{8}$ ou compartilhado); m) ano de implantação, n) tipo do público (sem-terra do $\mathrm{MST}^{9}$, atingidos por barragens ou ex-ocupantes de áreas indígenas); e o) região de implantação (Norte, Fronteira Oeste, Campanha, Sul e Metropolitana). Em duas etnografias, testouse o estado civil (p) e a religião(q) dos assentados.

Definimos os assentamentos como unidades de análise e obtivemos uma estimativa do percentual de evasão de lotes de 193 assentamentos, criados entre 1994 e 2002. As informações foram compiladas em 2005, no INCRA, complementados pelas informações do GRAC, com dados referentes a 2004.

As etnografias foram necessárias para aprofundar e constatar in loco o que chamamos "dimensão simbólica", tendo em vista que a maioria das variáveis analisadas, que agrupamos genericamente na idéia de "dimensão material”, não esclareceu o fenômeno da evasão, embora não tenhamos esgotado as análises possíveis nesta dimensão. A amostragem para as entrevistas combinou o método aleatório com a escolha de pessoas que possuíam uma posição diferenciada no assentamento, tais lideranças políticas e religiosas. Escolhemos dois assentamentos da Fronteira Oeste, criados em 1996, no município de Santana do Livramento, que apresentou o maior número de assentamentos na amostra. Embora com evasões díspares, eles foram contemplados com políticas públicas e infraestruturas muito semelhantes, e com público oriundo do mesmo acampamento.

\section{OS FATORES DA EVASÃO}

Nove (a, b, c, d, e, f, g, h, i) das 16 variáveis apresentaram fraca correlação com o percentual de evasão. Outras cinco $(\mathrm{j}, \mathrm{l}, \mathrm{m}, \mathrm{n}, \mathrm{o})$ foram quantificadas e avaliadas, não havendo, neste caso, necessidade da correlação estatística. As duas últimas $(\mathrm{p}, \mathrm{q})$ foram quantificadas nos estudos de caso.

A falta de correlação da evasão com os tempos transcorridos para acesso aos créditos e com a ausência de infra-estrutura nos indica que a vivência no acampamento, e o sofrimento que isto implica, parece tornar os assentados resistentes às situações de dificuldades materiais, as quais não foram suficientes para estimular a evasão, pois, mesmo que de forma precária e temporária, eles vão se adaptando a uma situação adversa.

A qualidade dos solos e o valor da terra são medidos de forma expedita pelo INCRA, através da metodologia das classes de capacidade de uso. A variável testada representa os solos em que é possível (ou recomendável) o cultivo de grãos, base da sobrevivência de parte da agricultura familiar. Sua fraca correlação com a evasão pode ser parcialmente explicada pelas matrizes produtivas cada vez mais adotadas pelos assentados, em especial o gado de

\footnotetext{
${ }^{4}$ Ver Bruno e Medeiros (2001) e Marques et al. (2002).

5 Programa Nacional de Fortalecimento da Agricultura Familiar, modalidade de créditos para assentados.

Associação Riograndense de Empreendimentos de Assistência Técnica e Extensão Rural, que presta serviço ao INCRA.

7 A COPTEC é uma cooperativa de técnicos, vinculada ao MST, que presta serviço ao INCRA.

${ }^{8}$ Gabinete da Reforma Agrária e Cooperativismo, órgão de terras estadual.

9 Movimento dos Trabalhadores Rurais Sem Terra.
} 
corte e de leite, em que a participação dos grãos acaba assumindo menor importância.

A Tabela 1 demonstra que os assentamentos federais apresentam uma evasão um pouco superior aos assentamentos do Estado, sendo que os compartilhados apresentam uma situação intermediária. Como as políticas para assentamentos são historicamente muito imbricadas entre o INCRA e o órgão estadual, tal diferença se deve somente ao maior \% de assentamentos novos na amostra do Estado.

Tabela 1. A evasão dos assentamentos do Rio Grande do Sul para cada executor

\begin{tabular}{|c|c|c|}
\hline Tipo & Número de familias & \% Evasão \\
\hline Estadual & 2.011 & 18,20 \\
\hline Federal & 4.484 & 23,95 \\
\hline Compartilhado & 892 & 21,08 \\
\hline Total da amostra & 7.387 & 22,04 \\
\hline
\end{tabular}

A Tabela 2 apresenta a evasão ao longo dos anos, demonstrando uma tendência à estabilização em, aproximadamente, 30\%, em média, mas, com 40\% nas regiões Bagé e Sul. Os assentamentos são atendidos pela EMATER ou pela COPTEC há muitos anos. Não há diferença na evasão entre estas duas prestadoras, o que não quer dizer que não haja influência da assistência técnica nos processos

Tabela 2. A evasão e o ano de criação dos assentamentos

\begin{tabular}{|crc|}
\hline Ano de criagão & Número de famílias & \% Evasão \\
\hline 1994 & 311 & 16,40 \\
\hline 1995 & 371 & 20,22 \\
\hline 1996 & 842 & 28,86 \\
\hline 1997 & 1.125 & 33,42 \\
\hline 1998 & 852 & 25,35 \\
\hline 1999 & 819 & 12,09 \\
\hline 2000 & 896 & 21,54 \\
\hline 2001 & 1.696 & 19,75 \\
\hline 2002 & 475 & 8,42 \\
\hline Total & 7.387 & 22,04 \\
\hline
\end{tabular}

${ }^{0}$ Enquanto servidor do órgão de terras do Estado, cadastrei, pessoalmente, mais de mil ocupantes de áreas indígenas e constatei que a grande maioria dos agricultores trabalhava no seu lote, sob o regime familiar.

sociais que se desenrolam lá, entre eles, a evasão, como veremos a seguir.

Quanto ao público, são representativas do senso comum as afirmações de que os sem-terra evadem mais e que isso ocorre porque eles, na verdade, não seriam agricultores, o que, evidentemente, não deveria ocorrer entre os outros públicos, que possuem uma reconhecida tradição na agricultura ${ }^{10}$. Entretanto, a evasão de 20 assentamentos formados por ex- ocupantes de áreas indígenas e atingidos por barragem (19 no Norte e um na Fronteira Oeste), demonstra uma coincidência com a evasão média do norte do Estado, onde a maioria dos assentamentos é composta por sem-terra.

A Região Norte apresenta a menor evasão do Estado, aproximadamente, $10 \%$ (Tabela 3 ). Dois fatores parecem explicar isso. Em primeiro lugar, é o local de origem de boa parte dos assentados, de modo que as relações sociais, especialmente de parentesco e de pertencimento, são mais facilmente construídas ou restabelecidas ali. Em segundo lugar, a região é mais favorável à reprodução da agricultura familiar, pelo maior dinamismo econômico (e, conseqüentemente, pela existência de mais infra-estrutura e mercados), e pela melhor condição edafo-climática para a produção agropecuária. Um recente estudo em assentamentos gaúchos (CONVÊNIO INCRA-RS/EMBRAPA/FAPEG, 2005) constatou que os assentamentos das regiões Sul, Fronteira Oeste e Bagé têm um baixo \% de área cultivada em seus lotes e apresentam menores produtividades de leite, milho e soja. Nestas regiões, encontramos solos menos adequados e um maior risco de seca, além de maior ocorrência de várzeas, geralmente problemáticas para a agricultura familiar. Por estas razões, estas terras têm menor valor.

Tabela 3. A evasão e as regiões do Rio Grande do Sul

\begin{tabular}{|c|c|c|}
\hline Região & Número de familias & \% Evasão \\
\hline Norte & 2.385 & 10,19 \\
\hline Porto Alegre & 778 & 25,45 \\
\hline Bagé & 1.296 & 33,33 \\
\hline Sul & 2.019 & 29,07 \\
\hline Fronteira Oeste & 909 & 18,48 \\
\hline Total & 7.387 & 22,04 \\
\hline
\end{tabular}




\section{A DIMENSÃO SIMBÓLICA DA REFORMA AGRÁRIA}

Como não obtivemos êxito em explicar a evasão apenas pela dimensão material, desenvolvemos uma análise da "dimensão simbólica" nos valendo do instrumental teórico da sociologia e da antropologia e adotando, em especial, a vertente denominada sociologia da crítica $^{11}$. Buscamos na noção de reciprocidade ${ }^{12}$ a chave de entendimento dos princípios envolvidos na construção da coesão social e no estancamento da evasão, complementadas pelas abordagens sobre comunidades e seus mecanismos de controle internos, de Wolf $(1976,2003 a)$ e Elias \& Scotson (2000).

Constatamos, nos dois assentamentos, uma grande importância da religião na vivência dos assentados, inclusive como forma de revitalização das relações de reciprocidade. No caso estudado, a ascensão evangélica parece se valer de uma certa disposição social dos camponeses, ao mesmo tempo em que toma parte no processo maior de pentecostalização da sociedade brasileira, especialmente entre as classes mais empobrecidas, entre outros fatores, pela sua eficácia na contenção do alcoolismo e, conseqüentemente, da violência.

Em suma, a noção de reciprocidade, com ênfase no parentesco, permite-nos compreender as estratégias de produção e reprodução de valores humanos com vistas ao estabelecimento de laços sociais, gerando um sentimento de pertencimento e uma crescente corporação, que, somadas aos mecanismos de controle interno, como verificamos em Elias e Wolf, conformam a própria idéia de comunidade, vista aqui como mantenedora dos assentados no campo, resistindo à atração do mundo urbano.

Por outro lado, as relações de reciprocidade assimétricas $^{13}$ como aquelas estabelecidas com fazendeiros, líderes religiosos, assistência técnica, órgãos de terra e MST, assim como as rixas internas (em alguns casos, representando reciprocidade negativa) nos ajudam a compreender a gestão dos conflitos e a tendência à desagregação pela qual muitos assentamentos são acometidos. Os assentados lançaram mão de estratégias de reconstrução da paz via parentesco, compadrio, ingresso na Assembléia de Deus (igreja pentecostal), negociação com o MST e via intensificação de relações de vizinhança com a comunidade circundante. Aqui, observamos a crescente ocupação dos as- sentamentos por pequenos agricultores vizinhos.

Estes processos são percebidos num ambiente de disputas de projetos corporativos que se explicitam na transposição do acampamento para o assentamento, entre eles, o projeto socialista-coletivista, do MST (cuja dominância promove a corporação provisória dos acampamentos), o projeto tradicional-camponês (manifestando-se enquanto resistência ao projeto socialista), os projetos rentistas, os empresariais e, por último, a contra-corporação, representada, especialmente, pela venda de lotes e pela evasão, propriamente.

Nas entrevistas, o discurso dos militantes do MST centra-se na desconstrução do pretenso caráter pequeno-burguês dos agricultores e reafirma o projeto coletivista, o qual é explicitado em uma de suas cartilhas (CONCRAB, 2001). Contudo, os estudos de caso revelaram as tentativas frustradas de formação de coletivos, pois não levaram em conta as relações de reciprocidade entre seus membros, qualificadores mesmo da categoria social camponesa. As inúmeras brigas e rixas que surgiram desses grupos, seja porque não tinham relações sólidas ou porque tinham estabelecido relações de reciprocidade negativa, acabaram deixando um terreno fértil para as conseqüências inesperadas da reforma agrária, tais como a evasão.

Por outro lado, a imposição do MST e do INCRA em direção ao coletivismo e para que os lotes vagos dos assentamentos fossem ocupados por acampados revela a hegemonia do projeto socialista, pelo menos no que tange à sua histórica influência no órgão federal. O propósito ideológico de lotes coletivos (presente até nas normativas do INCRA) assume, por vezes, roupagens técnicas, ampliando o seu poder simbólico de "convencimento" dos assentados, por meio do postulado de sua maior "racionalidade técnica".

A dominação do MST e a resistência camponesa que ela enseja foi discutida por vários autores ${ }^{14}$. Para Martins (2003), o que está em questão é que, na maioria dos casos, o coletivo possível é aquele composto pela família extensa. Os valores camponeses manifestam-se, por exemplo, na resistência aos lotes coletivos, que impedem a herança da terra, algo arraigado na tradição da agricultura familiar, pois está implícita aí outra concepção de propriedade, de trabalho e de família, relacionadas à prática da

${ }^{11}$ Dodier (1993) e Boltanski (1990).

${ }^{12}$ Sabourin (2004).

${ }^{13}$ Wolf (2003b).

${ }^{14}$ Silveira (2003), Navarro (2002), Martins (2003).

Raízes, Campina Grande, vol. 25, nº 1 e 2, p. 55-64, jan./dez. 2006 
reciprocidade e à religiosidade. Aqui, a terra pode até ser secundária; o essencial é a revitalização de um modo de vida calcado em valores fundantes da sociedade tradicional. Neste caso, para ele, a luta não seria primariamente por terra, e sim contra a desagregação das relações tradicionais, que se dá através de um processo de remodelação do assentamento que ele chamou de "reforma agrária dentro da reforma agrária”, isto é, o restabelecimento da família extensa enquanto espinha dorsal da comunidade, através da ocupação de lotes vagos.

Além de um projeto corporativo tradicional e um socialista, observamos a ocorrência em assentamentos de projetos empresariais e rentistas. A venda de lotes (e o arrendamento ${ }^{15}$ ) está bastante presente nos assentamentos do Rio Grande do Sul, o que, para Martins (2003), representa uma forma de driblar os efeitos perversos do desenraizamento. Concomitantemente, constatamos o fenômeno da diferenciação social e a invasão de fazendeiros nos assentamentos, arrendando e comprando lotes.

Os processos de corporação são reconhecidos e estimulados diferentemente pelos agentes de mediação do MST, de igrejas, técnicos e assentados. Com acúmulos diferenciados de capitais, estes agentes conformam um "campo de lutas" que também envolve projetos urbanizantes, ou mesmo, a transgressão final de qualquer tentativa de corporação, representada pela venda do lote. Tais conflitos, contudo, engendram, via trânsito entre as "cidades"16, os mecanismos de construção da paz, cuja materialização pode ser observada na composição dos grupos de relação e na ocupação dos lotes vagos.

No assentamento Apolo, o projeto socialista não conseguiu se estabelecer, ao passo que o projeto camponês vem ocupando espaços, embora de forma aparentemente mais lenta que no Santo Ângelo, devido aos conflitos que parecem ter facilitado o avanço da contra-corporação empresarial, associada à renda fundiária, ainda que de forma negociada com os camponeses. O Santo Ângelo experimentou o projeto socialista, o qual redundou em fracasso, predominando hoje o projeto camponês, ainda que hesitante, perante as investidas de fazendeiros.

Estas disputas de projetos, especialmente (mas não só) entre o projeto socialista e o tradicional, encontram seu momento crucial na vacância de um lote. O MST procu- ra inserir um acampado neste lote, o que, freqüentemente, provoca disputas internas com os assentados, que procuram fazer valer as relações religiosas e de reciprocidade, de parentesco e amizade na escolha dos novos ocupantes. Todavia, nestes momentos, para além da obrigatoriedade (muitas vezes, negociadas entre os projetos corporativos) do acampamento dos candidatos ao lote vago, geram-se relações clientelísticas com os mediadores. Os dois assentamentos estudados parecem estar equacionando, razoavelmente, a disputa por lotes, através do estabelecimento de um equilíbrio de forças entre católicos, MST e evangélicos.

O espaço de mediação ${ }^{17}$ é, por excelência, o palco destas disputas, em que, via de regra, ocorrem engajamentos nos diferentes projetos (socialista, camponês, empresarial, rentista). O controle deste espaço é, portanto, essencial para estes agentes, especialmente no que se refere à assistência técnica. Nos casos estudados, a COPTEC procura levar a cabo o projeto socialista, valendo-se do controle do crédito, um poderoso instrumento de violência simbólica. Para isso, disputa com os evangélicos na cobrança do dízimo. Aqui, para além da simples cobrança do "pedágio", surgem formas de coerção para que os assentados se "adaptem" às condições impostas, sejam técnicas, organizacionais ou comerciais.

Embora seja algo de difícil objetivação, as etnografias demonstraram que a assistência técnica parece ter contribuído para a evasão e lotes na medida em que, graças à sua precariedade técnica, falta de diálogo e postura em prol do coletivismo, não conseguiu responder adequadamente aos anseios dos assentados. Certamente, não é sem razão que, quando questionada, parcela significativa dos assentados afirmou que a assistência técnica era péssima ou inexistente.

\section{ROTATIVIDADE E EVASÃO NOS ESTUDOS DE CASO}

A Tabela 4 mostra os números da rotatividade e evasão nos dois assentamentos. Um aspecto semelhante é o fato de a rotatividade ser mais alta num primeiro momento e, depois, diminuir de ritmo. Ela nos traz pistas sobre um processo maior de construção da coesão social, es-

\footnotetext{
${ }^{15}$ Embora mereça um estudo específico, constatamos, ainda que preliminarmente, que o arrendamento em assentamentos parece vir, muitas vezes, associado à pluriatividade.

${ }^{16}$ Conforme Boltanski (1990).

${ }^{17}$ Neves (1998), Martins (2000) e Wolf (2003b) realizaram discussão específica sobre a medição em espaços rurais.
} 
pecialmente pela via do parentesco e da religião. Agentes com menor vínculo social, como aqueles não vinculados por parentesco e religião, solteiros e separados, têm mais mobilidade. As trocas para outros assentamentos, mesmo de casados, têm uma motivação especial de reencontro familiar, conforme constatamos nos relatos, podendo ser facilitadas pela rede de relações religiosas que se estabelece entre os assentamentos. Por outro lado, as exclusões resultantes da conformação destas redes, familiares ou religiosas, podem gerar saídas, às vezes, com o uso de violência física.

Tabela 4. Evasão e rotatividade nos assentamentos Santo Ângelo e Apolo

\begin{tabular}{llcc}
\hline \multicolumn{1}{c}{ Assentamento } & Apolo & Santo Ângelo & Média dos dois \\
total de lotes & 34 & 16 & 50 \\
\% permanência & 41 & 44 & 42,0 \\
\% rotatividade & 97,1 & 62,5 & 86,0 \\
\% evasão & 41,2 & 31,3 & 38,0 \\
\hline
\end{tabular}

A evasão no Santo Ângelo encontra-se na média das evasões nos assentamentos criados entre 1996 e 1998, em torno de 30\%, quando ocorreu uma leva de assentamentos em Santana do Livramento. Conforme visto anteriormente, não constatamos nenhuma correlação com a evasão nos dados secundários sobre infra-estrutura, porém, estas evasões ocorreram, todas, em lotes que sofrem algum grau de alagamento, corroborando com a justificativa de que todos os assentados levantaram, demonstrando uma especificidade não captada através dos dados secundários, pois há trechos que alagam e impedem a passagem do caminhão do leite e do transporte escolar. Contudo, algumas saídas ocorreram quando a estrada já estava melhor. Assim, mesmo em alguns casos, em que o discurso dos agentes apresenta uma motivação material, seja ela por um melhor solo ou por uma melhor infra-estrutura, consta- tamos outras motivações, por vezes implícitas, como a recorporação familiar ou a exclusão de uma comunidade tomando parte nas decisões dos agentes.

A maior evasão (41\%) rotatividade (97\%) no Apolo é explicada pela maior intensidade dos conflitos. Além de disputas por mulheres, os conflitos ocorreram pela hegemonia das terras e da água e, conseqüentemente, da relação com os arrendadores, pois parece ter havido uma maior cobiça por suas terras, devido à localização e ao tipo de terreno, comparando-o com o Santo Ângelo, indicando uma maior preponderância do projeto empresarial/rentista, ainda que negociado com camponeses engajados na ampliação de suas fronteiras de poder. A dificuldade de estabelecimento do projeto camponês e o próprio não estabelecimento do projeto socialista, por conta dos conflitos, demonstram que o Apolo está numa fase menos avançada da corporação camponesa.

A Tabela 5 apresenta a média da evasão e da rotatividade de solteiros e casados nos dois assentamentos, ambos com mesmo comportamento. Constatamos uma grande diferença na evasão entre solteiros $(38,9 \%)$, e casados $(16,4 \%)$. As diferenças em rotatividade são menores, com 66,7 e 42,5\%, respectivamente, indicando, ainda assim, uma clara tendência de maior mobilidade entre os solteiros.

Assumindo a construção da coesão social ou de uma rede de relações de reciprocidade, como fator preponderante para a permanência no assentamento, pelo menos como uma tendência, é razoável supor que o casamento permite o alargamento desta rede e, conseqüentemente, uma maior estabilização. Por outro lado, os agentes em busca de parceiros tendem a tornar o ambiente mais "conturbado", mesmo considerando o ocorrido no assentamento Apolo, onde as disputas por mulheres, entre casados, foram elemento complicador das rivalidades entre os grupos dentro do assentamento, corroborando para as mortes ocorridas.

No Santo Ângelo, conforme Tabela 6, a evasão dos evangélicos foi maior $(28,6 \%)$ que a dos católicos $(8,3 \%)$, ainda que a rotatividade tenha sido ligeiramente menor

Tabela 5. Evasão e estado civil - média dos dois assentamentos

\begin{tabular}{|c|c|c|c|c|c|c|}
\hline Estado Civil & Familias & Evadidos & $\begin{array}{c}\% \text { sobre total de sua } \\
\text { categoria }\end{array}$ & Rotativos & $\begin{array}{c}\% \text { sobre total de sua } \\
\text { categoria }\end{array}$ & $\%$ sobre total de lotes \\
\hline Casados & 73 & 12 & 16,4 & 31 & 42,5 & 62,0 \\
\hline Solteiros & 18 & 7 & 38,9 & 12 & 66,7 & 24,0 \\
\hline Total & 91 & 19 & & 43 & & 86,0 \\
\hline
\end{tabular}


Tabela 6. A evasão e a religião no assentamento Santo Ângelo

\begin{tabular}{|c|c|c|c|c|c|c|}
\hline Religiāo & Famílias & Evadidos & $\begin{array}{c}\% \text { sobre total de sua } \\
\text { categoria }\end{array}$ & Rotativos & $\begin{array}{c}\% \text { sobre total de sua } \\
\text { categoria }\end{array}$ & $\%$ sobre total de lotes \\
\hline Evangélicos & 14 & 4 & 28,6 & 5 & 35,7 & 31,25 \\
\hline Católicos & 12 & 1 & 8,3 & 5 & 41,7 & 31,25 \\
\hline Total & 26 & 5 & & 10 & & 62,5 \\
\hline
\end{tabular}

Tabela 7. A evasão e a religião do assentamento Apolo

\begin{tabular}{|c|c|c|c|c|c|c|}
\hline Religião & Familias & Evadidos & $\begin{array}{c}\text { \% sobre total de sua } \\
\text { categoria }\end{array}$ & Rotativos & $\begin{array}{c}\% \text { sobre total de sua } \\
\text { categoria }\end{array}$ & $\%$ sobre total de lotes \\
\hline Evangélicos & 17 & 0 & 0,0 & 5 & 29,4 & 14,7 \\
\hline Católicos & 48 & 14 & 29,2 & 28 & 58,3 & 82,4 \\
\hline Total & 65 & 14 & & 33 & & 97,1 \\
\hline
\end{tabular}

entre os evangélicos $(35,7 \%)$ do que entre os católicos $(41,7 \%)$. No Apolo (Tabela 7), embora ocorra um bom número de evangélicos - 17 famílias, com relação aos católicos - 48 famílias, a evasão entre os evangélicos é zero, só ocorrendo entre os católicos. A rotatividade entre os católicos $(58,3 \%)$ é quase o dobro daquela entre os evangélicos $(29,4 \%)$.

Com relação à religião, ocorrem processos diferentes nos dois assentamentos. Enquanto no Apolo não houve evasão de evangélicos, no Santo Ângelo ela foi preponderante (embora isto esteja representando, lá, a saída de quatro pessoas), o que indica que o processo de construção das relações de reciprocidade entre os evangélicos, mesmo sendo mais intenso que entre os católicos (os relatos do Santo Ângelo, inclusive dos católicos confirmam isso), não pode ser entendido de forma determinística, pois as configurações locais precisam ser avaliadas caso a caso.

A religião assume uma função primordial na coesão social, seja pela moral e pela normatização que impõe, seja pelo alargamento da rede de relações de reciprocidade que possibilita. A tendência de menor rotatividade entre os evangélicos corrobora com a idéia de que a pentecostalização tem se mostrado um fator importante de coesão social, através da realização de freqüentes cultos, do envolvimento dos praticantes em atividades coletivas e, fundamentalmente, porque dá conta de conter conflitos através do controle do alcoolismo e das drogas. A “organização" deste grupo também possibilita assumir espaços de poder dentro do assentamento e na relação com "os de fora”, notadamente com o INCRA.

\section{CONCLUSÕES}

1. A pesquisa forneceu elementos para testar a hipótese central e analisar as 16 variáveis. Uma primeira constatação se refere à importância que assume a idéia de rotatividade, a qual abarca a evasão, para que possamos compreender os processos sociais nos assentamentos, pois, muitas vezes, os agentes viabilizam formas de contenção de conflitos ou o estabelecimento de alianças sem, necessariamente, evadir do Programa de Reforma Agrária, especialmente quando há a possibilidade de troca de lotes dentro ou entre assentamentos.

2. Apesar das ponderações relativas aos limites de avaliação da dimensão material, neste estudo, entendemos que a baixa correlação dos fatores relacionados a esta dimensão aponta para a confirmação da hipótese central, em que constatamos a centralidade dos processos de desenvolvimento da sociabilidade por meio da construção e da ampliação de relações de reciprocidade, com vistas a um crescente fortalecimento de valores humanos e dos laços sociais, bastante relacionados ao parentesco, incluindo compadrio, às relações de vizinhança e religiosas, redundando no desenvolvimento de uma identidade "nós" ou de uma corporação. Estas relações são, pelo menos tendencialmente, responsáveis por balizar as condutas dos agentes sociais, inclusive com relação à decisão de evadir ou de trocar de lote.

3. Os assentamentos Apolo e Santo Ângelo vêm demonstrando a lenta consolidação do projeto camponês, ainda que de forma negociada com os outros projetos. Mesmo com percalços e vacilações, a cidade doméstica, 
como nos sugere Boltanski, indicadora de uma cultura camponesa e da preponderância de princípios potencialmente geradores de valores humanos, tais como a reciprocidade, demonstra a sua atualidade num mundo crescentemente voltado para o intercâmbio econômico e para os valores alienantes.

\section{REFERÊNCIAS BIBLIOGRÁFICAS}

BOLTANSKI, L. L' et la justice comme competences. Paris: Métailié, 1990.

BOURDIEU, P. Reprodução proibida: a dimensão simbólica da dominação econômica. In: O campo econômico: a dimensão simbólica da dominação. São Paulo: Papirus, 2000. p.93-119.

BRUMER, A; SOUZA, R. H. V; ZORZI, A. O futuro da juventude rural. In: Congresso da Associação LatinoAmericana de Sociologia Rural, 6., 2002, Porto Alegre. Anais... Porto Alegre: Associação Latino- Americana de Sociologia Rural, 2002. p.1365-1372.

BRUNO, R.; MEDEIROS, L. S. Percentuais e causas de evasão nos assentamentos rurais. Brasília: INCRA/MDA, 2001 (Cadernos da Terra, n.9).

CONFEDERAÇÃO DAS COOPERATIVAS DE REFORMA AGRÁRIA DO BRASIL. O que levar em conta para a organização do assentamento. Cadernos de Cooperação Agrícola, São Paulo, n.10, p.1-30, 2001.

CONVÊNIO INCRA-RS/EMBRAPA/FAPEG. Relatório final das atividades do convênio. 2005. Mimeografado.

DODIER, N. Agir em diversos mundos. In: CARVALHO, M. do C. B. de (Org.). Teorias da ação em debate. São Paulo: Cortez: FAPESP: Instituto de Estudos Especiais, PUC, 1993. p.77-109.

ELIAS, N. A sociedade dos indivíduos. Rio de Janeiro: Jorge Zahar Editor, 1994.

ELIAS, N.; SCOTSON, J. L. Os estabelecidos e os outsiders: sociologia das relações de poder a partir de uma pequena comunidade. Rio de Janeiro: Jorge Zahar Editor, 2000.
LEITE, S.; HEREDIA, B.; MEDEIROS, L. S (coord.). et al. Impactos dos assentamentos: um estudo sobre o meio rural brasileiro. Brasília: Instituto Interamericano de Cooperação para Agricultura: Núcleo de Estudos Agrários e Desenvolvimento Rural. São Paulo: UNESP, 2004.

MARQUES, A. C. H.; SANTO, C. R. E.; CEPÊDA, V. A . Indicadores sócio-econômicos das famílias desistentes em projetos de assentamentos rurais na região noroeste do Estado de São Paulo. In: Congresso da Associação Latino-Americana de Sociologia Rural, 6., 2002, Porto Alegre. Anais... Porto Alegre: Associação Latino-Americana de Sociologia Rural, 2002. p.1166-1177.

MARTINS, J. de S. Reforma Agrária: o impossível diálogo. São Paulo: USP, 2000.

O sujeito oculto: ordem e transgressão na reforma agrária. Porto Alegre: UFRGS, 2003.

MELLO, P. F. Evasão e rotatividade em assentamentos rurais no Rio Grande do Sul. Faculdade de Ciências Econômicas, Universidade Federal do Rio Grande do Sul, 2006. Dissertação Mestrado

NAVARRO, Z. Mobilização sem emancipação: as lutas sociais dos sem-terra no Brasil. In: SANTOS, B. de S. (org.). Produzir para viver: os caminhos da produção não capitalista. Rio de Janeiro: Civilização Brasileira, 2002. p.189-232.

NEVES, D. P. O desenvolvimento de uma outra agricultura: o papel dos mediadores sociais. In: FERREIRA, A. D. D.; BRANDENBURG, A. (org.). Para pensar outra agricultura. Curitiba: UFPR, 1998. p.147-168. (Pesquisa, 40).

SABOURIN, E. Dádiva e reciprocidade nas sociedades rurais contemporâneas. Tomo, São Cristóvão, n.7, p. 75104, 2004.

SILVEIRA, C. B. da. Organizações e a "lei de ferro das oligarquias": um estudo sobre os assentamentos rurais de reforma agrária. 2003. Porto Alegre: Faculdade de Ciências Econômicas/UFRGS 2003. Disponível em: http://www.ufrgs.br/pgdr. 10 Nov. 2004. Dissertação Mestrado 


\section{4 \\ Paulo Freire Mello}

WOLF, E. R. Sociedades camponesas. São Paulo: Zahar Editores, 1976.

Tipos de campesinato latino-americano: uma discussão preliminar. In: FELDMAN-BIANCO, B.; RIBEIRO, G. L. (org.). Antropologia e poder. Brasília: UNB, 2003a. p.117-144.

Parentesco, amizade e relações patrono-cliente em sociedades complexas. In: FELDMAN-BIANCO, B.; RIBEIRO, G. L. (org.). Antropologia e poder. Brasília: UNB, 2003b. p.93-113. 